\title{
SCIENTIFIC REPORTS

\section{Projecting Suitability and Climate Vulnerability of Bhutanitis thaidina (Blanchard) (Lepidoptera: Papilionidae) with Conservation Implications}

\author{
Shao-Ji Hu $\mathbb{1}^{1,2,5}$, Dong-Hui Xing ${ }^{3,5}$, Zhi-Xian Gong ${ }^{4}$ \& Jin-Ming Hu $\mathbb{D}^{1,2^{*}}$
}

Bhutanitis thaidina is an endemic, rare, and protected swallowtail in China. Deforestation, habitat fragmentation, illegal commercialised capture, and exploitation of larval food plants are believed to be the four major causes of population decline of $B$. thaidina in the recent decade. However, little attention was paid to the impact of climate change. This study used ecological niche factor analysis and species distribution model to analyse the current suitable areas for $B$. thaidina with BioClim variables as well as its future suitable areas under four future climate scenarios (represented by four Representative Concentration Pathways: RCP2.6, RCP4.5, RCP6.0, and RCP8.5). Statistical analysis was carried out to compare the possible area and altitude changes to the distribution of $B$. thaidina under changing climate. Our analyses showed that the suitable areas for $B$. thaidina are fragmented under the current climate, with four suitable centres in northwestern Yunnan, northeastern Yunnan and northwestern Guizhou, the western margin of Sichuan Basin, and Qinling mountains. Apart from further habitat fragmentation under climate change, slight range expansion (average 6.0-8.9\%) was detected under the RCP2.6 and RCP4.5 scenarios, while more range contraction (average 1.3-26.9\%) was detected under the RCP6.0 and RCP8.5 scenarios, with the two southern suitable centres suffering most. Also, a tendency of contraction $(2,500-3,500 \mathrm{~m})$ and upslope shift $(\sim 600 \mathrm{~m})$ in suitable altitude range were detected. The findings of this study supported the climate-vulnerable hypothesis of $B$. thaidina, especially under future climate like the RCP6.0 and RCP8.5 scenarios, in terms of contraction in suitable areas and altitude ranges. Conservation priority should be given to northwestern Yunnan, northeastern Yunnan, and northwestern Guizhou to alleviate the stress of massive habitat loss and extinction. Refugial areas should be established in all four suitable centres to maintain genetic diversity of $B$. thaidina in China.

Bhutanitis (Atkinson) (Lepidoptera: Papilionidae: Parnassiinae) is a group of world-class rare and regional endemic swallowtails (CITES Appendix II, ICUN enlisted) ${ }^{1,2}$ comprising only four known Sino-Himalayan species (Fig. 1), namely B. ludlowi Gabriel, B. lidderdalii (Atkinson), B. thaidina (Blanchard), and B. mansfieldi $(\text { Riley })^{3-11}$. China, especially its southwest part, is the diversity centre of these butterflies, containing the last three species $^{10,11}$.

Bhutanitis thaidina and B. mansfieldi are two National Grade II protected species of high conservation value endemic to southwest China ${ }^{12}$. In the past three decades, population decline has been observed in both species mainly due to deprivation of habitat linked to human activities. Deforestation for firewood, habitat fragmentation by agriculture and infrastructure expansion; illegal commercialised capturing for overseas markets; and

${ }^{1}$ Yunnan Key Laboratory of International Rivers and Transboundary Eco-security, Yunnan University, Kunming, 650500, China. ${ }^{2}$ Institute of International Rivers and Eco-security, Yunnan University, Kunming, 650500, China. ${ }^{3}$ School of Agriculture, Yunnan University, Kunming, 650500, China. ${ }^{4}$ Yulong Xueshan Provincial Nature Reserve, Yulong, 674100, China. ${ }^{5}$ These authors contributed equally: Shao-Ji Hu and Dong-Hui Xing. *email: hujm@ynu.edu.cn 


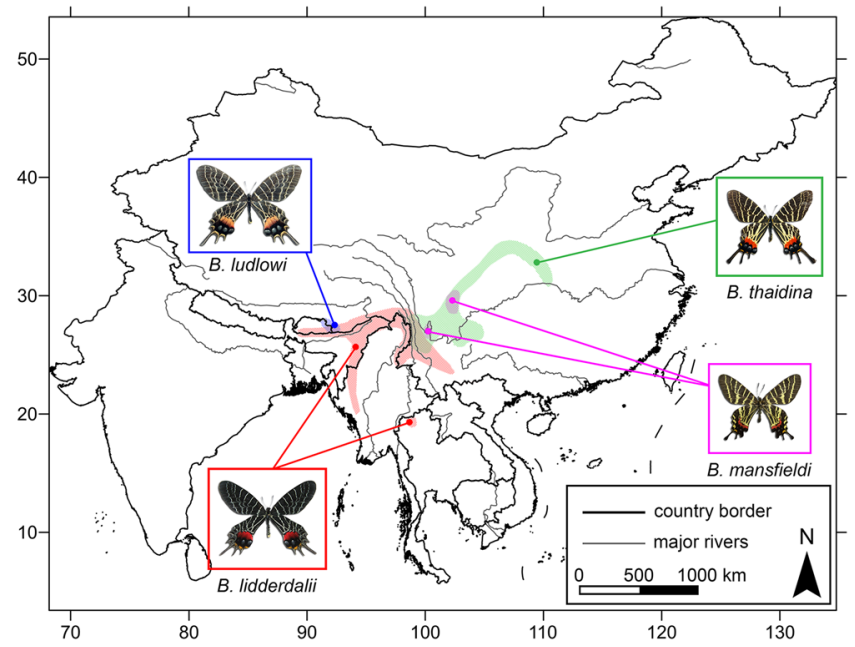

Figure 1. Tentative distribution range of four known species of Bhutanitis swallowtails. Photo of $B$. ludlowi (C) The Research Institute of Evolutionary Biology, Tokyo, Japan; photos of B. lidderdalii, B. thaidina, and B. mansfieldi $\odot$ Shao-Ji Hu.

exploitation of larval food plants (Aristolochia spp.) for traditional herbal medicines were believed to be the main aspects $^{4,13-15}$.

Habitat losses associated with human activities are undoubtedly imminent threats to the survival of certain populations of these two Bhutanitis species in China. In recent years, a few conservation studies were carried out on $B$. thaidina in attempt to alleviate the situation from biological and ecological aspects ${ }^{4,14,15}$, while little could be done with $B$. mansfieldi, a bionomic and distribution data-poor species. Apart from human activities, climate change is another factor which is attributed to many cases of extinction of rare and endemic species globally ${ }^{16,17}$. However, unfortunately, little attention has been paid to such slow but prolonged effect of climate change on the future of these butterflies.

Species distribution models (SDM) contains a range of effective analytical tools for simulating and visualising suitable areas (potential distribution range) of organisms, and has been widely applied to species of conservation interests as well as policy making over the past decade ${ }^{18-29}$. Among these methods, ecological niche factor analysis (ENFA) and maximum entropy (MaxEnt) modelling are the most frequently applied SDMs which project the suitable area of a species using the presence-only data without depending on bionomical parameters of the focal species, or being biased by pseudoabsence data ${ }^{30,31}$.

In an attempt to fill the gap in conservation of Bhutanitis, the present study chose B. thaidina, a data-rich species as our model, analysed the current distribution and the future distribution shift under different climatic change scenarios ${ }^{32}$ using SDMs of ENFA and MaxEnt. The results will provide us an overview of its suitable areas in China and facilitate our understanding of how the suitable areas would shift in the process of climate change. The findings of the present study are beneficial to conservation management in current time as well as to formulate countermeasures to alleviate population decline of this rare butterfly in the future.

\section{Materials and Methods}

Data sources. Species distribution points were extracted from specimen collections (Natural History Museum, London; Zoologisches Forschungsinstitute und Museum Alexander König, Bonn; Institute of Zoology, Chinese Academy of Sciences (CAS); Kunming Institute of Zoology, CAS; Southwest Forestry University; and private collections), literature ${ }^{3,4,9,14,33-37}$, and web databases and photo records (www.papc.cn; www.flickr.com) (Table S1). In total, 61 distribution points for B. thaidina were obtained (Fig. 2). All coordinates were transformed to decimal degrees and stored in an Excel spreadsheet for further use.

Nineteen BioClim ${ }^{38}$ variables were used to represent the current climate features (averaged over 1970-2000), the 19 BioClim variables and the altitude mask with 30 arc seconds resolution were obtained from the WorldClim database (www.worldclim.org). All data was further cropped by the political boundary of the People's Republic of China, and will be referred as 'environmental factors' hereafter.

The CMIP5 climate projections under the IPCC-AR5 (the $5^{\text {th }}$ Assessment Report of the Intergovernmental Panel on Climate Change) frame were used to represent the future climate ${ }^{32}$. Four representative concentration pathways (RCPs), RCP2.6, RCP4.5, RCP6.0, and RCP8.5 were selected to simulate possible climate changes ${ }^{32}$. Data with 30 arc seconds resolution was also obtained from the WorldClim database and cropped by the political boundary of the People's Republic of China.

Species distribution points and environmental factors were transformed into two formats, with the IDRISI format for ENFA analysis ${ }^{31,39}$ and the ASCII format for MaxEnt analysis ${ }^{40}$.

Frequency and importance of environmental factors. Ecological niche factor analysis (ENFA) was performed in Biomapper $4.0^{31}$ for current climate only, as future models cannot be inferred from current distribution data. To minimise possible negative influence of autocorrelation between environmental factors, correlation 


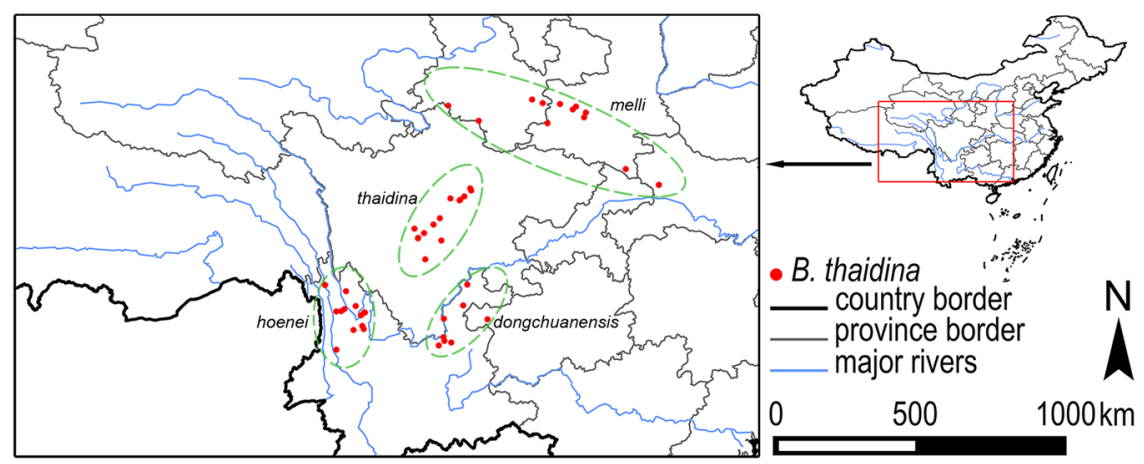

Figure 2. Distribution of the presence data points of $B$. thaidina in China with designation of subspecies range.

of the 20 environmental factors were tested using a UPGMA dendrogram in Biomapper 4.0, and factors with correlation coefficients above 0.95 were removed from the dataset. When removing autocorrelated factors, those representing short-period extremes (e.g., minimum temperature of the coldest month, maximum precipitation of the wettest month) were removed, while those representing longer periods (e.g., mean temperature of the coldest quarter, precipitation of the driest quarter) were kept, as such type of environmental factors often play an important role in species distribution.

In an attempt to analyse the distribution prevalence of $B$. thaidina, values of previously screened environmental factors in the distribution area of $B$. thaidina and the entirety of China were extracted using DIVA-GIS 5.7 (www.dive-gis.org) ${ }^{41}$. The distribution frequencies were calculated in Biomapper 4.0. The importance of the environmental factors was measured using the jackknife method in MaxEnt 3.4.1 with 1,000 iterations ${ }^{42,43}$.

Species distribution model (SDM). Environmental factors with ENFA scores over 0.2 were selected and assigned to the MaxEnt 3.4.1 ${ }^{40}$ to project suitable areas (current and future climate variables were analysed separately) based on the presence data points, among which $25 \%$ were extracted for random testing. The logistic output method was selected to estimate the distribution (or presence) probability of $B$. thaidina considering certain assumptions of species' prevalence and sampling effort ${ }^{44}$. The resultant map was saved as ASCII format and then redrawn using Surfer 10.0 (Golden Software Inc., Golden, CO, USA). Model robustness was evaluated using the receiver operation curve (ROC) and the area under the ROC curve (AUC) ${ }^{45,46}$, where the AUC value [AUC $\left.\in(0,1)\right]$ approaching 1.0 is usually considered acceptable, whereas it should be rejected when approaching the random turquoise line of $0.5^{47}$.

Statistical analyses. The number of grid cells (further transformed into area using 1 grid cell $=1 \mathrm{~km}^{2}$ ) as well as their elevation property were extracted in ArcGIS 10 (ESRI, USA) from projection maps under the current climate and the four future climate scenarios in both the $2050 \mathrm{~s}$ and the $2070 \mathrm{~s}$. Comparative bar charts for suitable areas and curve line charts for suitable altitude range were made to $2050 \mathrm{~s}$ vs. current, $2070 \mathrm{~s}$ vs. current, and $2070 \mathrm{~s}$ vs. $2050 \mathrm{~s}$, mainly focusing on suitability ranks from 0.5 to over 0.8 .

\section{Results}

Key environmental factors. Nine environmental factors, Alt, Bio5, Bio6, Bio8, Bio9, Bio13, Bio14, Bio18, and Bio19, were removed from the dataset due to strong autocorrelation (correlation coefficients $>0.95$ ) in UPGMA dendrogram test. ENFA analysis using the remaining eleven environmental factors further excluded Bio15 and Bio17 as all scores of ecological factors were under 0.2 (Table 1). The final remaining nine environmental factors, Bio1, Bio2, Bio3, Bio4, Bio7, Bio10, Bio11, Bio12, and Bio16, were key influential factors of the current suitability for distribution of $B$. thaidina in China (Table 1 ).

Frequency distribution of $B$. thaidina against the nine key influential environmental factors for the entirety of China showed evident preference for each factor. For temperature factors, $B$. thaidina occurs in areas where annual mean temperature (Bio1) ranges between $1-17^{\circ} \mathrm{C}$, mean temperature of the warmest quarter (Bio10) ranges between $10-23^{\circ} \mathrm{C}$, and mean temperature of the coldest quarter (Bio11) ranges between $-9-10^{\circ} \mathrm{C}$ (Fig. S1). For precipitation factors, B. thaidina occurs in areas where annual precipitation (Bio12) ranges between 630-1,400 $\mathrm{mm}$ and precipitation of the wettest quarter (Bio16) ranges between 250-750 mm (Fig. S1). For temperature variabilities, $B$. thaidina mainly occurs in areas where mean diurnal temperature range (Bio2) varies between $7-12{ }^{\circ} \mathrm{C}$, temperature annual range (Bio7) varies between $22-35^{\circ} \mathrm{C}$, relatively higher isothermality (Bio3) and low temperature seasonality (Bio4) (Fig. S1).

Current suitable areas. The MaxEnt analysis produced a projection with the training AUC $=0.983$ and the testing $\mathrm{AUC}=0.981$, representing a credible result of the suitability distribution for $B$. thaidina under the current climate.

On the large scale, the current suitable areas for B. thaidina are still confined to west China, as mirrored by its actual distribution localities (Fig. 2). Four areas with higher suitability were identified. (1) Northwest Yunnan. This area occupies the Hengduan Mountains in Yunnan and southwest Sichuan, including the mountains separated by the upper Irrawaddy, Salween, Mekong, and Yangtze watersheds. The eastern edge of this area 


\begin{tabular}{|l|l|l|l|l|l|l|l|l|}
\hline \multirow{3}{*}{ EFs } & F1 & F2 & F3 & F4 & F5 & F6 & F7 & F8 \\
\cline { 2 - 9 } & $\mathbf{6 2 \%}$ & $\mathbf{2 4} \%$ & $\mathbf{5 \%}$ & $\mathbf{5 \%}$ & $\mathbf{2} \%$ & $\mathbf{1} \%$ & $\mathbf{1} \%$ & $\mathbf{1} \%$ \\
\hline Bio1 & 0.16 & 0.62 & -0.52 & 0.09 & 0.21 & 0.06 & -0.04 & 0.47 \\
\hline Bio2 & -0.28 & -0.10 & -0.23 & 0.28 & 0.12 & 0.04 & 0.07 & 0.02 \\
\hline Bio3 & 0.38 & 0.08 & 0.11 & -0.10 & -0.05 & -0.03 & -0.01 & -0.01 \\
\hline Bio4 & -0.47 & 0.41 & -0.13 & 0.12 & -0.35 & 0.56 & -0.42 & -0.35 \\
\hline Bio7 & -0.48 & 0.09 & 0.47 & -0.71 & -0.25 & -0.07 & -0.17 & -0.08 \\
\hline Bio10 & -0.06 & -0.64 & 0.13 & 0.27 & 0.39 & -0.53 & 0.54 & 0.14 \\
\hline Bio11 & 0.32 & 0.05 & 0.49 & -0.55 & -0.78 & 0.63 & -0.70 & -0.80 \\
\hline Bio12 & 0.28 & 0.06 & 0.30 & -0.07 & 0.01 & 0.01 & -0.04 & 0.00 \\
\hline Bio15 & -0.07 & -0.04 & 0.13 & -0.05 & 0.00 & 0.00 & -0.01 & 0.01 \\
\hline Bio16 & 0.33 & 0.00 & -0.24 & 0.06 & 0.01 & 0.01 & 0.05 & -0.02 \\
\hline Bio17 & -0.02 & -0.09 & -0.04 & -0.04 & -0.01 & -0.01 & 0.02 & 0.02 \\
\hline
\end{tabular}

Table 1. Score matrix of current key environmental factors screened by ENFA analysis. EF = environmental factors, $\mathrm{F}=$ ecological niche factors identified by ENFA analysis. Marginality $=1.43$, speciality $=7.12$, tolerance $=0.14$.

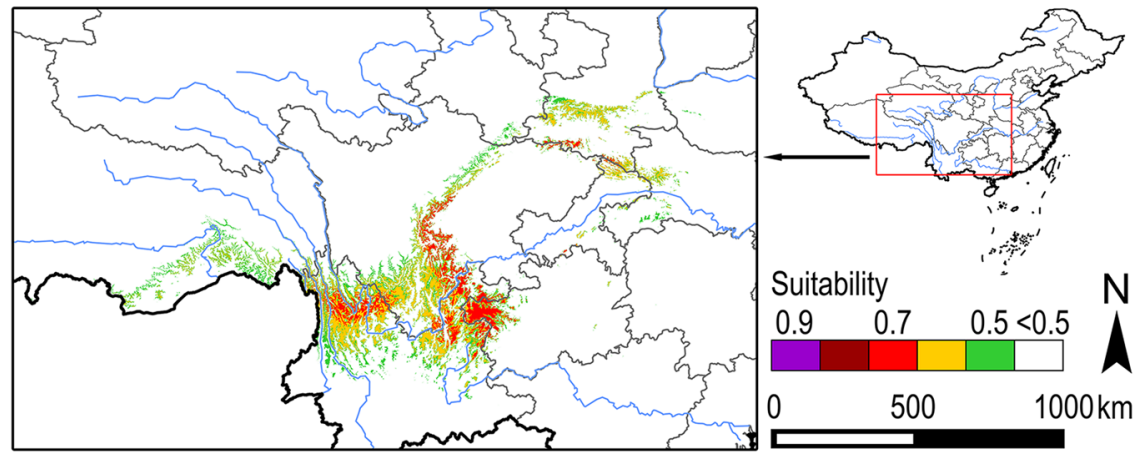

Figure 3. Suitable areas for B. thaidina in China under current climate condition.

approximately reaches Anning River (a branch of upper Yangtze River), while the southern edge of it reaches east Dali to Yunlong (Fig. 3). (2) Northeast Yunnan, northwest Guizhou, and the western edge of Sichuan Basin. A larger stripe-shaped area initiates from Dongchuan and Luquan of east Yunnan altiplano and the west part of Bijie area in northwest Guizhou, runs northward to the north of Yaan, and then turns northeastwardly to the border of south Gansu, with a gradient reduction of suitability (Fig. 3). (3) Taibai Shan and Daba Shan areas in south Shaanxi. Two small patches are separated by the Qinling ridge, reaching the southern edge of Hanzhong Plain in the north, and the northern edge of Sichuan Basin in the south (Fig. 3). (4) East Daba Shan and Shennongjia areas in the juncture of northeast Chongqing and northwest Hubei. A smaller patch with relatively lower suitability (Fig. 3).

At smaller and local scales, the suitable areas for B. thaidina are highly fragmented, even within the four isolated patches mentioned above. Despite ridges of high mountains and deep valleys of large rivers cutting these patches into separate pieces, the suitable areas for $B$. thaidina are further isolated by complex terrains in a small range (Fig. 3).

Future change of suitable range. The MaxEnt analysis produced a projection with the training AUC $=0.983-0.986$ and the testing AUC $=0.986-0.987$, representing credible results of the suitability distributions for B. thaidina under the four future climate scenarios (four RCPs) in the $2050 \mathrm{~s}$ and the $2070 \mathrm{~s}$, respectively.

In the $2050 \mathrm{~s}$, the overall distribution pattern of the suitable areas showed obvious but non-radical changes. The change under RCP2.6 scenario is very limited, making the distribution pattern very similar to that under the current climate, but the 0.7 grade suitable areas expanded in northwest Yunnan, occupying the 0.6 grade suitable areas under the current climate; while the 0.7 grade suitable areas retreated in southwest Sichuan bordering with northeast Yunnan (Fig. 4A). Under the RCP4.5 scenario, the distribution pattern remained the same with that under the RCP2.6 scenario, except for an elevation of suitability grade (0.8-0.9) in the western edge of the Sichuan basin (Fig. 4B). Under the RCP6.0 and RCP8.5 scenarios, distribution pattern changed more obviously with the low-medium suitability grades (0.5-0.6) retreating in the southern edge and lower-altitude areas of the distribution range, but a higher suitability grade (0.8-0.9) appearing in northwest Yunnan and the western edge of the Sichuan basin (Fig. 4C,D). Gain of high suitability grade (0.7) was also detected in south Qinling under the RCP8.5 scenario (Fig. 4D).

In the $2070 \mathrm{~s}$, the overall distribution pattern of the suitable areas under the RCP2.6 and the RCP4.5 scenarios almost remained the same as that in the $2050 \mathrm{~s}$ (Fig. 5A,B). However, dramatic changes to the suitability 

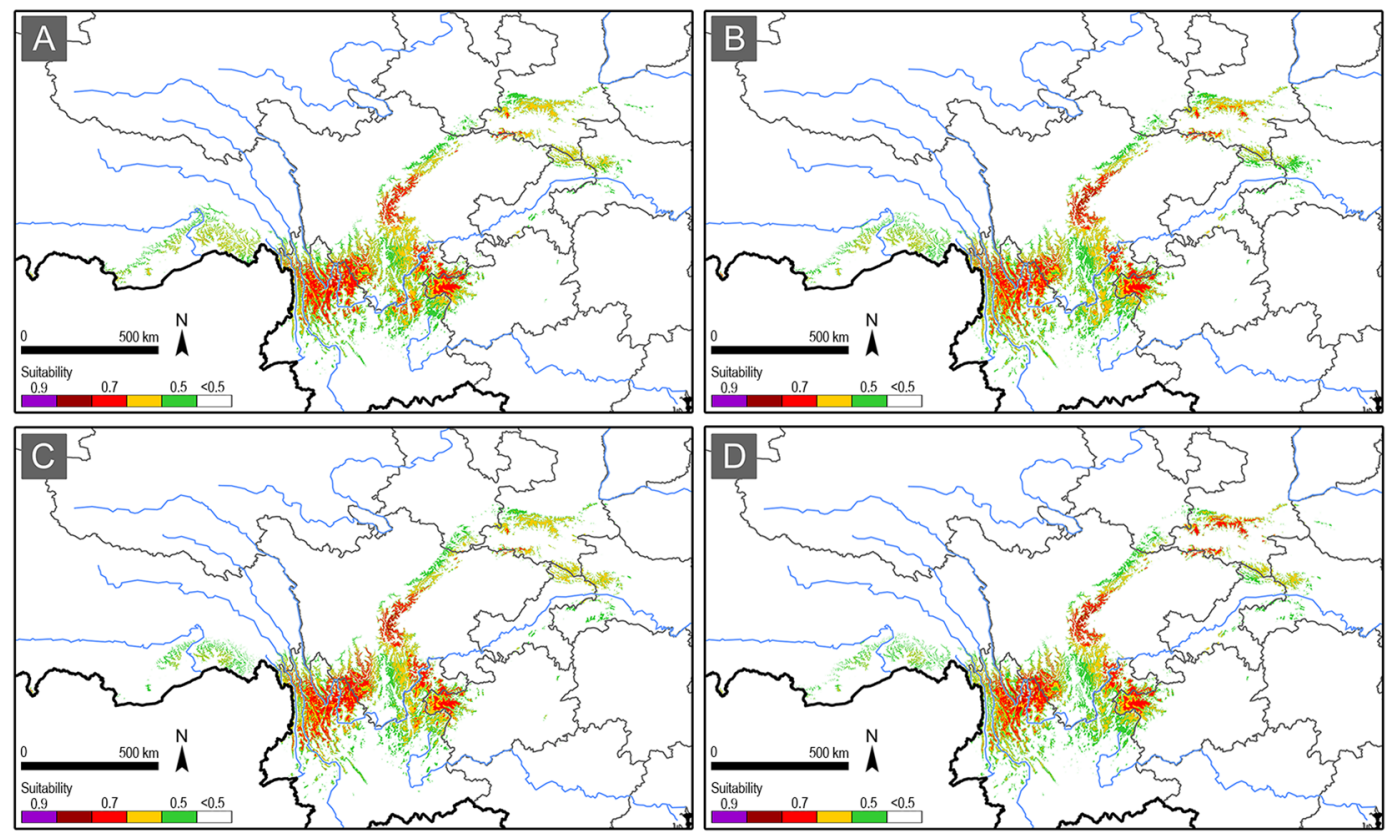

Figure 4. The suitable areas for B. thaidina in China in the $2050 \mathrm{~s}$ under the RCP2.6 (A), RCP4.5 (B), RCP6.0 (C), and RCP8.5 (D) scenarios.
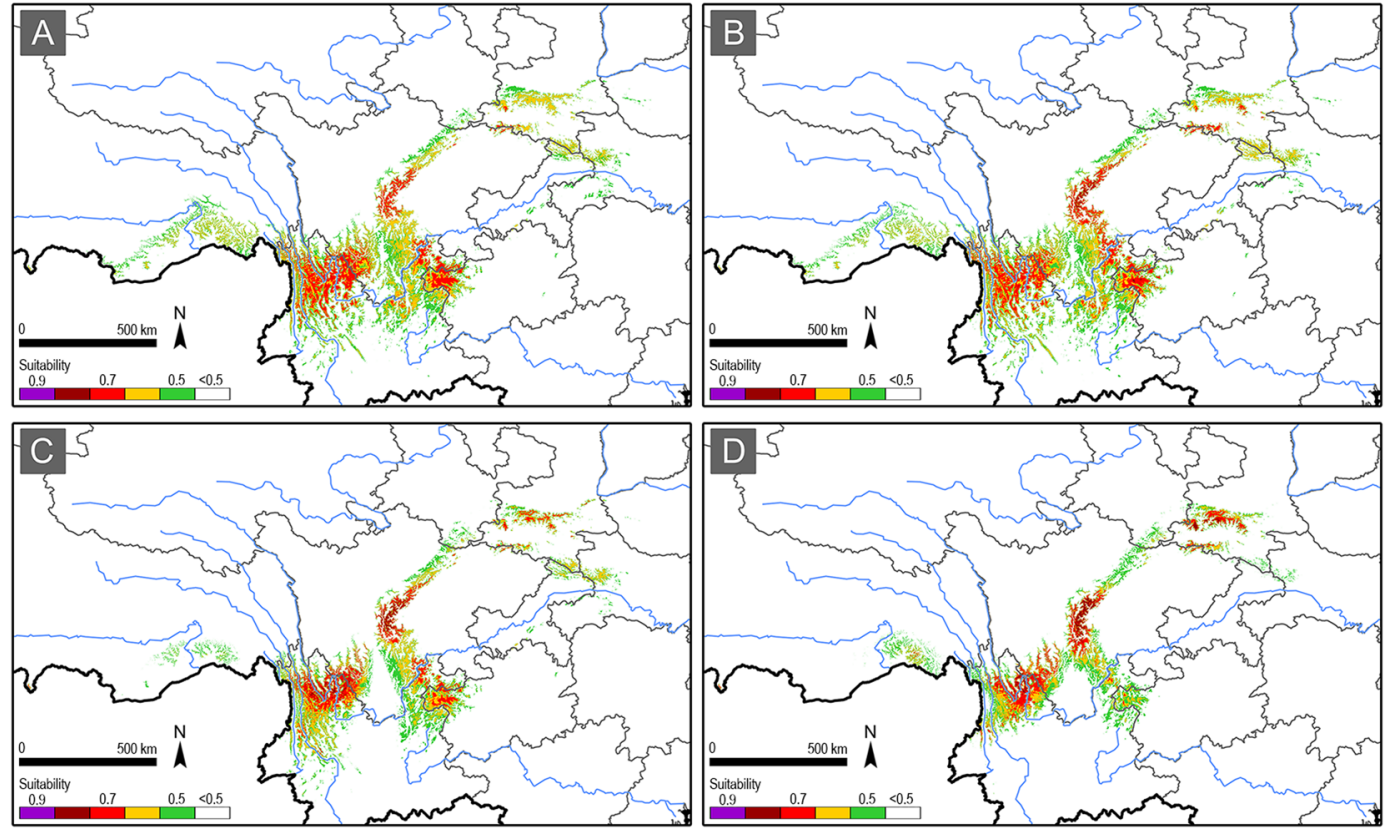

Figure 5. The suitable areas for B. thaidina in China in the $2070 \mathrm{~s}$ under the RCP2.6 (A), RCP4.5 (B), RCP6.0 (C), and RCP8.5 (D) scenarios.

distribution under the RCP6.0 and the RCP8.5 scenarios were detected. Not only the low-medium suitability grades (0.5-0.6) largely retreated in the southern margin and the lower-altitude areas, the medium-high suitability grades (0.6-0.8) also dramatically retreated in the southern portion of the distribution range, especially in northwest Yunnan, northeast Yunnan, and northwest Guizhou (Fig. 5C,D). Similar to the 2050 s, gain of higher suitability grade (0.8-0.9) was detected in south Qinling under the RCP8.5 scenario (Fig. 5D).

Future change of suitable area and altitudes. Our quantitative analysis of the change of suitable areas showed that, in the $2050 \mathrm{~s}$, suitable areas of the 0.5-0.6 and 0.7-0.9 ranks all increased under all future climate scenarios, with the $0.5-0.6$ rank increased most $\left(3.32-16.07 \times 10^{3} \mathrm{~km}^{2}\right.$, average $\left.16.6 \%\right)$ and the $0.8-0.9$ rank increased least (1.06-2.88 $\times 10^{3} \mathrm{~km}^{2}$, average 95,487.5\%); however, suitable areas of 0.6-0.7 rank decreased 

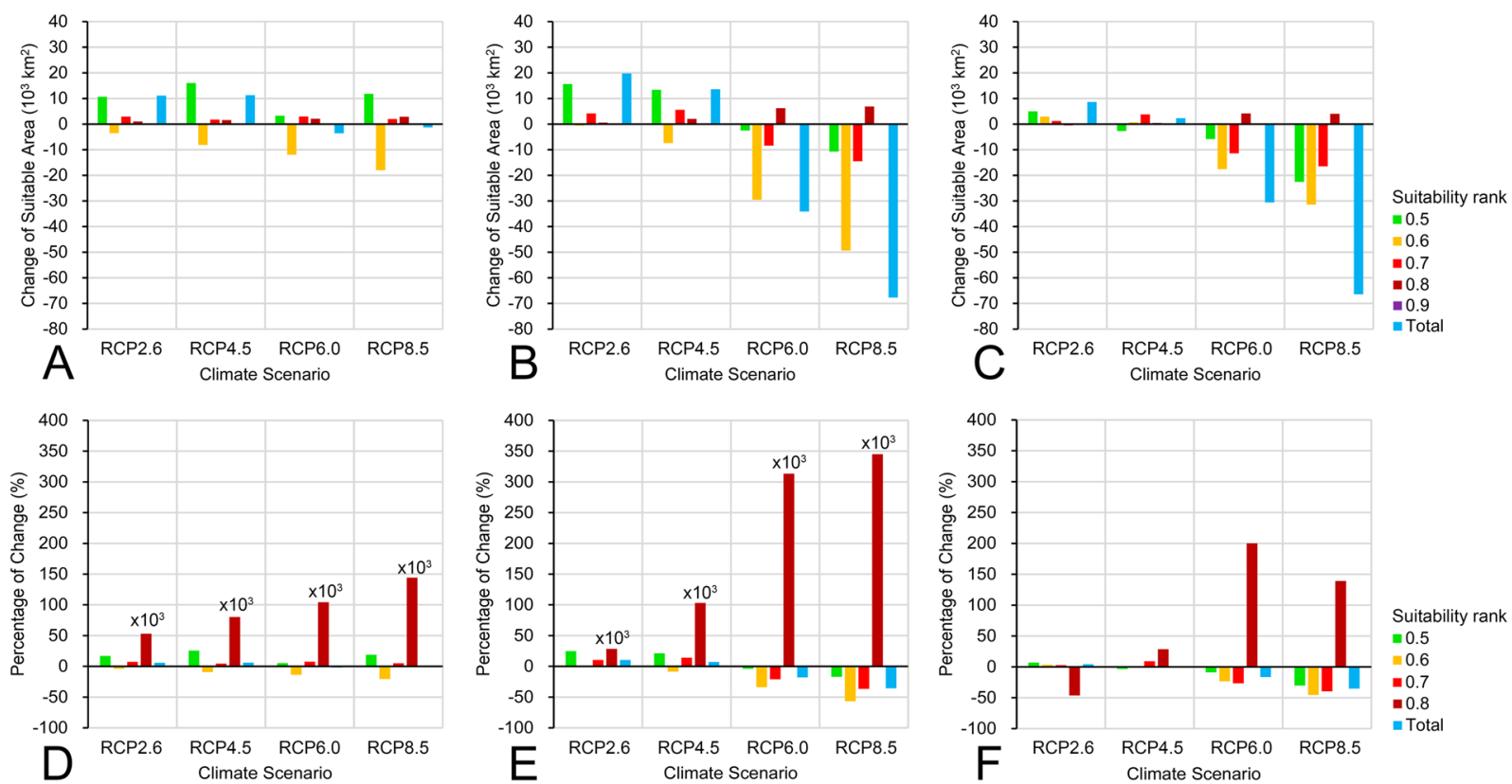

Figure 6. The change of suitable areas $\left(10^{3} \mathrm{~km}^{2}\right)(\mathbf{A}-\mathbf{C})$ and the percentage of suitable area change (\%) (D-F) for B. thaidina in China: (A,D) 2050 s vs. current, (B,E) 2070 s vs. current, (C,F) 2070 s vs. 2050 s.

significantly under all future climate scenarios (3.51-17.98 $\times 10^{3} \mathrm{~km}^{2}$, average $\left.12.0 \%\right)$ (Fig. 6A,D). The total suitable areas for $B$. thaidina increased $11.14 \times 10^{3} \mathrm{~km}^{2}(5.9 \%)$ and $11.30 \times 10^{3} \mathrm{~km}^{2}(6.0 \%)$ under RCP2.6 and RCP4.5 scenarios, while they decreased $3.55 \times 10^{3} \mathrm{~km}^{2}(1.9 \%)$ and $1.27 \times 10^{3} \mathrm{~km}^{2}(0.7 \%)$ under RCP6.0 and RCP 8.5 scenarios (Fig. 6A,D).

In the $2070 \mathrm{~s}$, suitable areas of the $0.5-0.6$ and $0.7-0.8$ ranks increased under RCP2.6 and RCP4.5 scenarios (13.39-15.64 $\times 10^{3} \mathrm{~km}^{2}$ and $4.17-5.59 \times 10^{3} \mathrm{~km}^{2}$ respectively; average $23.1 \%$ and $12.3 \%$ respectively) but decreased under RCP6.0 and RCP8.5 scenarios $\left(3.96-17.04 \times 10^{3} \mathrm{~km}^{2}\right.$ and $21.11-36.49 \times 10^{3} \mathrm{~km}^{2}$ respectively; average $10.5 \%$ and $28.8 \%$ respectively), the suitable areas of the $0.8-0.9$ rank increased under all future climate scenarios $\left(0.57-6.90 \times 10^{3} \mathrm{~km}^{2}\right.$, average 197,500.0\%); however, suitable areas of 0.6-0.7 rank decreased significantly under all future climate scenarios $\left(0.58-49.37 \times 10^{3} \mathrm{~km}^{2}\right.$, average $\left.25.0 \%\right)$ (Fig. 6B,E). The total suitable areas for $B$. thaidina increased $19.80 \times 10^{3} \mathrm{~km}^{2}(10.5 \%)$ and $13.63 \times 10^{3} \mathrm{~km}^{2}(7.2 \%)$ under RCP2.6 and RCP4.5 scenarios, while they decreased $34.12 \times 10^{3} \mathrm{~km}^{2}(18.0 \%)$ and $67.67 \times 10^{3} \mathrm{~km}^{2}(35.7 \%)$ under RCP6.0 and RCP 8.5 scenarios (Fig. 6B,E).

Comparison between the $2070 \mathrm{~s}$ and the $2050 \mathrm{~s}$ showed a similar tendency, the total suitable areas for $B$. thaidina increased $8.66 \times 10^{3} \mathrm{~km}^{2}(4.3 \%)$ and $2.33 \times 10^{3} \mathrm{~km}^{2}(1.2 \%)$ under RCP2.6 and RCP4.5 scenarios, while they decreased $30.57 \times 10^{3} \mathrm{~km}^{2}(16.4 \%)$ and $66.40 \times 10^{3} \mathrm{~km}^{2}(35.3 \%)$ under RCP6.0 and RCP 8.5 scenarios (Fig. 6C,F).

Analysis of frequency distribution change of suitable altitudes showed that, under RCP2.6 and RCP4.5 scenarios, the frequency distribution of suitable altitudes did not shift obviously but were more contracted between 2,500-3,200 $\mathrm{m}$ in the $0.5-0.6$ and 0.6-0.7 ranks, while they shifted to 2,600-3,500 $\mathrm{m}$ in the 0.7-0.8 rank (Fig. 7). The frequency of suitable altitudes in the $2050 \mathrm{~s}$ is almost equal to that in the current, while the frequency of suitable altitudes in the $2070 \mathrm{~s}$ was significantly higher than that in the $2050 \mathrm{~s}$ (Fig. 7). Under RCP6.0 scenario, the frequency distribution patterns were similar to those under the preceding scenarios, but the peak frequency of the suitable altitudes was lower, with that in the $2070 \mathrm{~s}$ even significantly lower than the $2050 \mathrm{~s}$ in the $0.6-0.7$ and the 0.7-0.8 ranks (Fig. 7). It is noticeable that under the RCP8.5 scenario, the peak frequency of the suitable altitudes was further significantly lowered, especially in the $2070 \mathrm{~s}$ (Fig. 7).

\section{Discussion}

Distribution shift and climate vulnerability. Based on the EGV frequency distribution characters, $B$. thaidina mainly occurs in temperate climate zones with less precipitation, relatively higher diurnal temperature range, and lower temperature seasonality (Fig. S1). Such habitat is represented by montane broadleaf forest and subalpine evergreen needle leaf forest, which may extend from $2,000 \mathrm{~m}$ to below the treeline in west China, with its lower and upper limits varying from the south to the north ${ }^{48,49}$. With climate change, the habitat belt will be forced to 'move' upslope $e^{50}$. However, shift rates of the lower and upper limits are not expected to be the same, and such asymmetric shift rates will eventually result in a decline in suitable altitude belt ${ }^{51}$.

Although some research indicates that species will move or expand their ranges upslope and poleward with climate change ${ }^{52-56}$, our analysis implied that $B$. thaidina would more likely suffer from rapid habitat compression or be driven to extinction during this process ${ }^{57-59}$. On the one hand, the distribution shift rate of species can hardly keep up with the pace of habitat shift and compression ${ }^{51}$; and on the other hand, ascent of the upper part of its suitable range will be limited by unfavourable climate or soil condition (e.g., increased precipitation, 
$0.5-0.6$
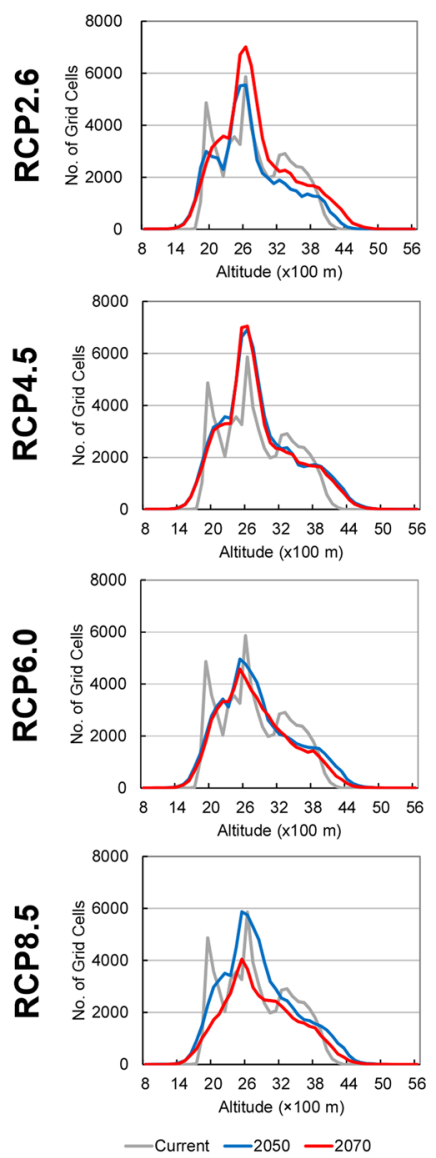

$0.6-0.7$
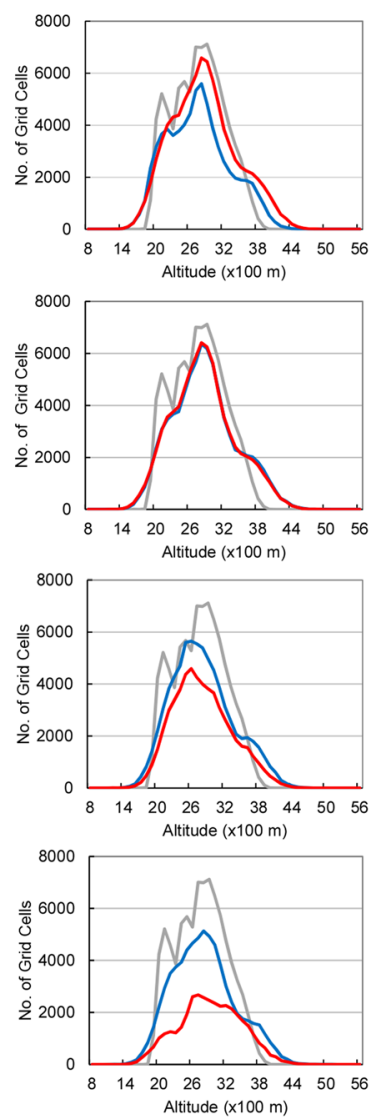

0.7-0.8
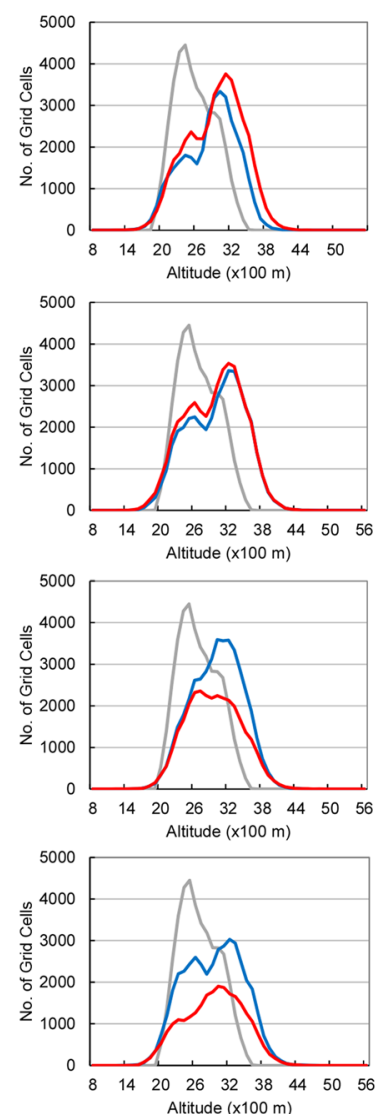

$>0.8$
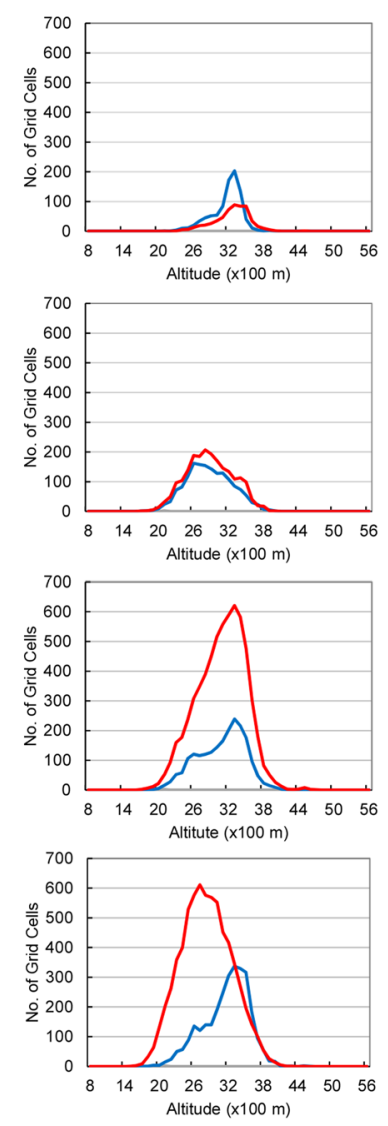

Figure 7. The frequency distribution of suitable altitudes for B. thaidina in China under different suitability ranks $(0.5-0.6,0.6-0.7,0.7-0.8,>0.8)$ and the change under four future climate scenarios (RCP2.6, RCP4.5, RCP6.0, RCP8.5) in the $2050 \mathrm{~s}$ and $2070 \mathrm{~s}$.

erosion linked to permafrost degeneration $)^{60}$. More practically, the ability of $B$. thaidina to move from one habitat to another is largely limited by lack of connecting mountain ridges with suitable habitat, since its suitable area is already highly fragmented even under the current climate. Our speculation on this issue was similarly demonstrated in the tropical forests ${ }^{61}$.

The adult is the only stage at which all butterflies can achieve distant movement, while other stages from egg through pupa can only stay in the same locality. Such a life history further reduces their ability to escape from bad climate. Bhutanitis, a univoltine group with a maximum adult stage of only 2.5 months per year ${ }^{14,62}$, can hardly defend themselves against any climate induced incidents, including extreme precipitation, long-lasting drought, or even forest fire ${ }^{63,64}$. The extinction of B. lidderdalii on Doi Chiang Dao of northern Thailand in 1983, caused by a severe forest fire in the dry season as a result of the 1982-1983 El Niño, is a most recent case (A. M. Cotton, pers. comm.).

As a result, the distribution shift for $B$. thaidina in light of climate change would compress its suitable habitat and further reduce its refugial areas (Figs 3-7). Globally, the climate vulnerability of $B$. thaidina is much higher under the RCP6.0 and RCP8.5 scenarios compared to that under the RCP2.6 and RCP4.5 scenarios. Regionally, climate vulnerability of the two southern distribution centres is higher than the two northern ones (Figs 4 and 5) (discussed in detail below).

Biodiversity significance. The current suitable areas revealed a patchy and highly fragmented distribution pattern for B. thaidina (Fig. 3), while future projection showed a compressed and further fragmented distribution pattern (Figs 4 and 5). Nonetheless, as the present study only applied climatic factors in SDM simulation, the actual distribution pattern of $B$. thaidina could be more fragmented on an unsuitable matrix when availability of host resources and vegetation are taken into consideration. In population genetics, highly fragmented distribution would result in a reduction of gene flow and genetic diversity ${ }^{65-71}$.

B. thaidina is a morphologically variable species with four subspecies recognised to date: ssp. thaidina in west Sichuan, ssp. hoenei Bryk in northwest Yunnan, ssp. melli Bryk in Qinling and Taibai Shan (probably also in Shennongjia), and ssp. dongchuanensis Lee in northeast Yunnan and northwest Guizhou 3,9,11,33,35,72 (Fig. 2), mirroring our identification of four suitability centres (Figs 3-5). The biological and ecological issue underpinning the taxonomic complexity is that each subspecies possesses a distinct genetic profile. The genetic and 
morphological profiles altogether constitute the entire biodiversity integrity of B. thaidina in China, and any degeneration or loss of such profiles will directly lead to a loss of biodiversity of this endemic species.

The distribution pattern of suitable areas for B. thaidina is highly fragmented, thus making each subspecies a metapopulation comprised of multiple scattered and isolated smaller local populations. A recent population genetic analysis suggested very low genetic diversity among all populations of $B$. thaidina in $C$ hina $^{73}$, implying vulnerability to degeneration or extinction in the dynamic wild ${ }^{74}$. In the process of climate change, the future distribution pattern of $B$. thaidina will be further fragmented and isolated, which would inevitably bring more restriction to the gene flow between the four distribution centres as well as within each one. Our future projections showed significant suitability loss in the distribution range of ssp. dongchuanensis in northeast Yunnan and northwest Guizhou, followed by ssp. hoenei in northwest Yunnan (Figs 4 and 5), making these two subspecies more prone to extinction under the RCP6.0 and RCP8.5 scenarios, compared to the other two subspecies.

Conservation implications. The present study showed that the fragmented suitable areas for B. thaidina will undergo further fragmentation and reduction in the process of climate change (Figs 3-5). Hence, maintaining current existing suitable areas is vital to the conservation of this rare species.

To conserve $B$. thaidina with genetic integrity, conservation strategies must firstly take all four suitable centres into equal consideration, as each suitable centre represents a distinct subspecies of $B$. thaidina in China. Next, combining the degree of rarity and vulnerability, priority should be given to areas with ssp. dongchuanensis and ssp. hoenei, which will be the most threatened in the future (Figs 4 and 5); followed by ssp. melli, which is only found in a narrow area in Qinling (Fig. 3); and ssp. thaidina being of least concern.

Availability of larval food plants is also crucial in conservation of $B$. thaidina. This species shows a strong host association in nature, and subspecies use different Aristolochia species, e.g., in northwest Yunnan and most parts of west Sichuan, B. thaidina mainly uses $A$. moupinensis and A. delavayi ${ }^{3,14}$, while using $A$. mandshuriensis in the Qinling Mountain area ${ }^{4}$. These food plant species have being exploited for traditional Chinese herbal medicines until recent years ${ }^{75}$. Such long lasting exploitation has already depleted wild resources of Aristolochia in some places $^{2}$. Apart from human exploitation, deforestation of virgin forests on the median altitude to subalpine mountains is another important threat to wild Aristolochia resources, as most Aristolochia species are shade plants. Deforestation will also destroy the suitable habitats of Aristolochia.

Establishing refugial areas for B. thaidina could be an optimal in situ protection method. When selecting sites for refugial areas, vegetation surveys must be performed in advance to ensure the best vegetation type being included, e.g., Quercus stands associated with multiple local Aristolochia species ${ }^{76}$. However, the optimal planning of refugial areas for $B$. thaidina must rely on future in-depth research involving bionomics, dispersal capability, food plant adaptability, habitat matrix composition and connectivity, as well as a thorough evaluation of population genetic diversity.

By establishing refugial areas in such vegetation types, not only could $B$. thaidina be well conserved, but also many other rare, regional endemic, or data-poor butterflies can be protected under the umbrella-species effect $^{77,78}$, e.g., Bhutanitis lidderdalii, B. mansfieldi, Byasa daemonius (Alphéraky), B. plutonius (Oberthür), B. rhadinus (Jordan) associated with Aristolochia ${ }^{62}$; as well as numerous Theclini hairstreaks (Lycaenidae) associated with Quercus ${ }^{79}$.

When in situ protection faces the challenge of high and progressive habitat fragmentation due to climate change found in the present study, coupled with the limited genetic diversity described earlier ${ }^{73}$, other measures must also be considered in the future to increase the genetic diversity and evolution flexibility of $B$. thaidina to respond to rapid environmental changes in a certain area. Possible measures include introducing ex situ populations containing new genetic profiles from other distribution areas, or even releasing laboratory genetic recombinants ${ }^{80}$.

Received: 30 October 2018; Accepted: 11 October 2019;

Published online: 28 October 2019

\section{References}

1. CITES. Appendices I, II, and III; valid from 4 October 2017, https://cites.org/eng/app/appendices.php (2018).

2. IUCN. The IUCN Red List of Threatened Species. 2018-1, http://www.iucnredlist.org/ (2018).

3. Chou, I. A study on the rare butterflies of the genus Bhutanitis (Lepidoptera: Papilionidae) with descriptions of two new species. Entomotaxonomia 14, 48-54 (1992).

4. Gao, K., Li, X. S., Guo, Z. Y. \& Zhang, Y. L. The bionomics, habitat requirements and population threats of the butterfly Bhutanitis thaidina in Taibai Mountain. Journal of Insect Conservation 18, 29-38, https://doi.org/10.1007/s10841-014-9612-1 (2014).

5. Häuser, C. L. et al. Papilionidae - revised GloBIS/GART species checklist (2nd draft), http://www.insects-online.de/frames/papilio.htm (2005).

6. Inayoshi, Y. A Check List of Butterflies in Indo-China, Chiefly from Thailand, Laos \& Vietnam. Last Update 2018.08.31, http://yutaka. it-n.jp/ (2018).

7. Kunte, K., Sondhi, S. \& Roy, P. Butterflies of India, v. 2.53. Indian Foundation for Butterflies, http://www.ifoundbutterflies.org/ (2018).

8. Nose, Y. Notes on Teinopalpus imperialis and Bhutanitis lidderdalii (Lepidoptera, Papilionidae) from northernmost Myanmar. Notes on Eurasian Insects 2, 33-45 (1998).

9. Sorimachi, Y. Geographical and individual variations of the Bhutanitis thaidina. Apollo 3, 77-87 (1994).

10. Wu, C. S. \& Hsu, Y. F. Butterflies of China (The Straits Publishing \& Distributing Group, 2017).

11. Bollino, M. \& Racheli, T. Butterflies of the World: Supplement 20 (Goeck \& Evers, 2012).

12. NFGA. List of Wildlife under Special State Protection, http://www.forestry.gov.cn/main/3951/content-1063898.html (2018).

13. He, Q. J. \& Yi, C. H. In Symposium of the 8th Congress of Chinese Entomological Society. 145-146 (2007).

14. Yi, C. H., He, F. X., He, Q. J. \& Wang, L. The biological characteristics of Bhutanitis yulongensis Chou. Chinese Journal of Applied Entomology 48, 1505-1508 (2011).

15. Yi, C. H., He, Q. J., Wang, L., Chen, Y. \& Yi, W. Distribution, endangered reasons and protective research of Bhutanitis thaidina. Hubei Agricultural Sciences 50, 2851-2854, https://doi.org/10.3969/j.issn.0439-8114.2011.14.013 (2011). 
16. Sinervo, B. et al. Erosion of lizard diversity by climate change and altered thermal niches. Science 328, 894-899, https://doi. org/10.1126/science.1184695 (2010).

17. Thomas, C. D. et al. Extinction risk from climate change. Nature 427, 145-148, https://doi.org/10.1038/nature02121 (2004).

18. Akhter, S. et al. Habitat distribution modelling to identify areas of high conservation value under climate change for Mangifera sylvatica Roxb. of Bangladesh. Land Use Policy 60, 223-232, https://doi.org/10.1016/j.landusepol.2016.10.027 (2017).

19. Bosso, L. et al. Nature protection areas of Europe are insufficient to preserve the threatened beetle Rosalia alpina (Coleoptera: Cerambycidae): evidence from species distribution models and conservation gap analysis. Ecological Entomology 43, 192-203, https://doi.org/10.1111/een.12485 (2018).

20. Eaton, S. et al. Adding small species to the big picture: Species distribution modelling in an age of landscape scale conservation. Biological Conservation 217, 251-258, https://doi.org/10.1016/j.biocon.2017.11.012 (2018).

21. Evans, T. G., Diamond, S. E. \& Kelly, M. W. Mechanistic species distribution modelling as a link between physiology and conservation. Conservation Physiology 3, cov056, https://doi.org/10.1093/conphys/cov056 (2015).

22. Fajardo, J., Lessmann, J., Bonaccorso, E., Devenish, C. \& Muñoz, J. Combined use of systematic conservation planning, species distribution modelling, and connectivity analysis reveals severe conservation gaps in a megadiverse country (Peru). PLoS ONE $\mathbf{9}$, e114367, https://doi.org/10.1371/journal.pone.0114367 (2014).

23. Guisan, A. et al. Predicting species distributions for conservation decisions. Ecology Letters 16, 1424-1435, https://doi.org/10.1111/ ele.12189 (2013).

24. Kujala, H., Moilanen, A. \& Gordon, A. Spatial characteristics of species distributions as drivers in conservation prioritization. Methods in Ecology and Evolution 9, 1121-1132, https://doi.org/10.1111/2041-210x.12939 (2018).

25. Scoble, J. \& Lowe, A. J. A case for incorporating phylogeography and landscape genetics into species distribution modelling approaches to improve climate adaptation and conservation planning. Diversity and Distributions 16, 343-353, https://doi. org/10.1111/j.1472-4642.2010.00658.x (2010).

26. Thomaes, A., Kervyn, T. \& Maes, D. Applying species distribution modelling for the conservation of the threatened saproxylic Stag Beetle (Lucanus cervus). Biological Conservation 141, 1400-1410, https://doi.org/10.1016/j.biocon.2008.03.018 (2008).

27. Villero, D., Pla, M., Camp, D., Ruiz-Olmo, J. \& Brotons, L. Integrating species distribution modelling into decision-making to inform conservation actions. Biodiversity Conservation 26, 251-271, https://doi.org/10.1007/s10531-016-1243-2 (2017).

28. Wilson, C. D., Roberts, D. \& Reid, N. Applying species distribution modelling to identify areas of high conservation value for endangered species: A case study using Margaritifera margaritifera (L.). Biological Conservation 144, 821-829, https://doi. org/10.1016/j.biocon.2010.11.014 (2011).

29. Zacarias, D. \& Loyola, R. Distribution modelling and multi-scale landscape connectivity highlight important areas for the conservation of savannah elephants. Biological Conservation 224, 1-8, https://doi.org/10.1016/j.biocon.2018.05.014 (2018).

30. Elith, J. \& Graham, C. H. Do they? How do they? Why do they differ? On finding reasons for differing performances of species distribution models. Ecography 32, 66-77, https://doi.org/10.1111/j.1600-0587.2008.05505.x (2009).

31. Hirzel, A. H., Hausser, J., Chessel, D. \& Perrin, N. Ecological-niche factor analysis: how to compute habitat-suitability maps without absence data? Ecology 83, 2027-2036, https://doi.org/10.1890/0012-9658(2002)083[2027:enfaht]2.0.co;2 (2002).

32. IPCC. Climate Change 2014: Synthesis Report. 151 (Geneva, Switzerland, 2014).

33. Lee, C. L. Some new species of Rhopalocera in China. Entomotaxonomia 7, 191-194 (1985).

34. Lee, C. L. Yunnan Butterflies (China Forestry Press, 1995).

35. Li, C. L. A new species and four new subspecies of the family Parnassiidae from Yunnan, China (Rhopalocera: Parnassiidae). Journal of Southwest Agricultural University 16, 101-105, https://doi.org/10.13718/j.cnki.xdzk.1994.02.003 (1994).

36. Liu, P. A rare butterfly, Bhutanitis thaidina, was found in Hualong Shan Nature Reserve. Shaanxi. Forestry 2011, 46-46, https://doi. org/10.3969/j.issn.1003-2460.2011.04.058 (2011).

37. Yang, Q. S., Cai, J. Z. \& Tang, C. M. The protected species, rare species, and world-famous butterflies in Xiaolong Shan, Gansu. Practical Forestry Technology 2014, 32-35, https://doi.org/10.13456/j.cnki.lykt.2014.10.012 (2014).

38. Hijmans, R. J., Cameron, S. E., Parra, J. L., Jones, P. G. \& Jarvis, A. Very high resolution interpolated climate surfaces for global land areas. International Journal of Climatology 25, 1965-1978, https://doi.org/10.1002/joc.1276 (2015)

39. Eastman, J. R. Idrisi for Windows 2.0 user's guide (Clark University, 1997).

40. Phillips, S. J., Anderson, R. P. \& Schapire, R. E. Maximum entropy modeling of species geographic distributions. Ecological Modelling 190, 231-259, https://doi.org/10.1016/j.ecolmodel.2005.03.026 (2006).

41. Hijmans, R. J., Guarino, L. \& Mathur, P. DIVA-GIS Version 7.5 Manual, 2012).

42. Bosso, L. et al. Loss of potential bat habitat following a severe wildfire: a model based rapid assessment. International Journal of Wildland Fire 27, 756-769, https://doi.org/10.1071/wf18072 (2018).

43. Sinopoli, M., Lauria, V., Garofalo, G., Maggio, T. \& Cillari, T. Extensive use of Fish Aggregating Devices together with environmental change influenced the spatial distribution of a tropical affinity fish. Scientific reports 9, https://doi.org/10.1038/s41598-019-41421-9 (2019).

44. Elith, J. et al. A statistical explanation of MaxEnt for ecologists. Diversity and Distributions 17, 43-57, https://doi.org/10.1111/j.14724642.2010.00725.x (2010)

45. Smeraldo, S. et al. Ignoring seasonal changes in the ecological niche of non-migratory species may lead to biases in potential distribution models: lessons from bats. Biodiversity and Conservation 27, 2425-2441, https://doi.org/10.1007/s10531-018-1545-7 (2018).

46. Préau, C., Trochet, A., Bertrand, R. \& Isselin-Nondereu, F. Modeling potential distributions of three European amphibian species comparing ENFA and Maxent. Herpetological Conservation and Biology 13, 91-104 (2018).

47. Fielding, A. H. \& Bell, J. F. A review of methods for the assessment of prediction errors in conservation presence/absence models. Environment Conservation 24, 38-49, https://doi.org/10.1017/s0376892997000088 (1997).

48. Guo, K. et al. China vegetation cassification: concept, approach and applications. Phytocoenologia 48, 113-120, https://doi. org/10.1127/phyto/2017/0166 (2018).

49. Liu, H. X. The vertical zonation of mountain vegetation in China. Geographica Sinica 73, 267-279 (1981).

50. Wong, M. H., Duan, C. Q., Long, Y. C., Luo, Y. M. \& Xie, G. Q. How will the distribution and size of subalpine Abies georgei forest respond to climate change? A study in Northwest Yunnan, China. Physical Geography 31, 319-335, https://doi.org/10.2747/02723646.31.4.319 (2010).

51. Forster, P. The potential negative impacts of global climate change on tropical montane cloud forests. Earth-Science Reviews 55, 73-106, https://doi.org/10.1016/s0012-8252(01)00056-3 (2001).

52. Chen, I. C., Hill, J. K., Ohlemüller, R., Roy, D. B. \& Thomas, C. D. Rapid range shifts of species associated with high levels of climate warming. Science 333, 1024-1026, https://doi.org/10.1126/science.1206432 (2011).

53. Forister, M. L. et al. Compounded effects of climate change and habitat alteration shift patterns of butterfly diversity. PNAS 107, 2088-2092, https://doi.org/10.1073/pnas.0909686107 (2010).

54. Thomas, C. D. Climate, climate change and range boundaries. Diversity and Distributions 16, 488-495, https://doi.org/10.1111/ j.1472-4642.2010.00642.x (2010).

55. VanDerWal, J. et al. Focus on poleward shifts in species' distribution underestimates the fingerprint of climate change. Nature Climate Change 3, 239-243, https://doi.org/10.1038/nclimate1688 (2013). 
56. Wright, S. J., Muller-Landau, H. C. \& Schipper, J. The future of tropical species on a warmer planet. Conservation Biology 23, 1418-1426, https://doi.org/10.1111/j.1523-1739.2009.01337.x (2009).

57. Chen, I. C. et al. Asymmetric boundary shifts of tropical montane Lepidoptera over four decades of climate warming. Global Ecology and Biogeography 20, 34-45, https://doi.org/10.1111/j.1466-8238.2010.00594.x (2011).

58. Colwell, R. K., Brehm, G., Cardelús, C. L., Gilman, A. C. \& Longino, J. T. Global warming, elevational range shifts, and lowland biotic attrition in the wet tropics. Science 322, 258-261, https://doi.org/10.1126/science.1162547 (2008).

59. Elsen, P. R. \& Tingley, M. W. Global mountain topography and the fate of montane species under climate change. Nature Climate Change 5, 772-776, https://doi.org/10.1038/nclimate2656 (2015).

60. Cannone, N., Sgorbati, S. \& Guglielmin, M. Unexpected impacts of climate change on alpine vegetation. Frontiers in Ecology and the Environment 5, 360-364, https://doi.org/10.1890/060141 (2007).

61. Senior, R. A., Hill, J. K. \& Edwards, D. P. Global loss of climate connectivity in tropical forests. Nature Climate Change 9, 623-626, https://doi.org/10.1038/s41558-019-0529-2 (2019).

62. Igarashi, S. On the life history of Bhutanitis lidderdalii Atkinson in Bhutan (Lepidoptera, Papilionidae). Tyô to Ga 40, 1-21 (1989).

63. Sloan, S., Locatelli, B., Wooster, M. J. \& Gaveau, D. A. L. Fire activity in Borneo driven by industrial land conversion and drought during El Niño periods, 1982-2010. Global Environmental Change 47, 95-109, https://doi.org/10.1016/j.gloenvcha.2017.10.001 (2017).

64. Taufik, M. et al. Amplification of wildfire area burnt by hydrological drought in the humid tropics. Nature Climate Change 7 , 428-431, https://doi.org/10.1038/nclimate3280 (2017).

65. Broeck, A. V. et al. Gene flow and effective population sizes of the butterfly Maculinea alcon in a highly fragmented, anthropogenic landscape. Biological Conservation 209, 89-97, https://doi.org/10.1016/j.biocon.2017.02.001 (2017).

66. Harrisson, K. A. et al. Fine-scale effects of habitat loss and fragmentation despite large-scale gene flow for some regionally declining woodland bird species. Landscape Ecology 27, 813-827, https://doi.org/10.1007/s10980-012-9743-2 (2012).

67. Pavlova, A. et al. Severe consequences of habitat fragmentation on genetic diversity of an endangered Australian freshwater fish: A call for assisted gene flow. Evolutionary Applications 10, https://doi.org/10.1111/eva.12484 (2017).

68. Sexton, J. P., Hangartner, S. B. \& Hoffmann, A. A. Genetic isolation by environment or distance: which pattern of gene flow is most common? Evolution 68, 1-15, https://doi.org/10.1111/evo.12258 (2014)

69. Stevens, K., Harrisson, K. A., Hogan, F. E., Cooke, R. \& Clarke, R. H. Reduced gene flow in a vulnerable species reflects two centuries of habitat loss and fragmentation. Ecosphere 9, e02114, https://doi.org/10.1002/ecs2.2114 (2018).

70. Wan, H. Y., Cushman, S. A. \& Ganey, J. L. Habitat fragmentation reduces genetic diversity and connectivity of the Mexican spotted owl: a simulation study using empirical resistance models. Genes 9, 403, https://doi.org/10.3390/genes9080403 (2018).

71. Raphael, M. G. et al. Genetic analyses of historic and modern marbled murrelets suggest decoupling of migration and gene flow after habitat fragmentation. Proceedings of the Royal Society (Ser. B) 277, 697-706, https://doi.org/10.1098/rspb.2009.1666 (2010).

72. Bryk, F. Neue Parnassiiden aus dem Zoologischen Reichsmuseum Alexander König in Bonn. Parnassiana 5, 50-54 (1938).

73. Zhao, J. et al. Genetic diversity of Bhutanitis thaidina Blanchard, based on mitochondrial COI and NDI. Journal of Fujian Agricultural and Forestry University (Natural Science Edition) 46, 387-391, https://doi.org/10.13323/j.cnki.j.fafu(nat.sci.).2017.04.004 (2017).

74. Haddad, N. M. et al. Habitat fragmentation and its lasting impact on Earth's ecosystems. Science Advances 1, e1500052, https://doi. org/10.1126/sciadv.1500052 (2015).

75. CFDA. Bulletin of Adverse Reactions of Medicines, http://samr.cfda.gov.cn/WS01/CL1989/11278.html (2004).

76. Lee, C. L. First report of ecology and phylogenetics studies of two Chinese Bhutanitis (Bhutanitis mansfieldi et B. thaidina). Yadoriga 156, 17-26 (1986).

77. Ozaki, K. et al. A mechanistic approach to evaluation of umbrella species as conservation surrogates. Conservation Biology 5 , 1507-1515, https://doi.org/10.1111/j.1523-1739.2006.00444.x (2006).

78. Roberge, J.-M. \& Angelstam, P. Usefulness of the umbrella species concept as a conservation tool. Conservation Biology 18, 76-85, https://doi.org/10.1111/j.1523-1739.2004.00450.x (2004).

79. Koiwaya, S. \& Ueda, K. The Zephyrus Hairstreaks of the World. (Mushi-Sha, 2007).

80. Scriber, J. M. Climate-driven reshuffling of species and genes: potential conservation roles for species translocations and recombinant hybrid geneotypes. Insects 5, 1-61, https://doi.org/10.3390/insects.501001 (2014).

\section{Acknowledgements}

The authors thank Motoki Saito of the Butterfly Society of Japan for providing the copyright photos of B. ludlowi for this study; Chongqing Natural History Museum, Chongqing, China; Kunming Institute of Zoology, CAS, Kunming, China; Institute of Zoology, CAS, Beijing, China; Trustees of the Natural History Museum (London, UK); and Zoologisches Forschungsinstitute und Museum Alexander Koenig, Bonn for access to museum collections of $B$. thaidina. The authors also wish to thank Fei-Ling Yang (Yunnan University, Kunming, China) for assistance in data analysis; Yutaka Inayoshi (Chiang Mai, Thailand) for his assistance in translating Japanese literature; Adam M. Cotton (Chiang Mai, Thailand) for sharing museum photos with distribution data of $B$. thaidina and improving the earlier drafts of this article; Mark J. Scriber (Michigan State University, MI, USA) and the other anonymous reviewer for excellent comments which again improved the quality of this article. This study was funded by the National Key R\&D Programme of China (2017YFC0505200), the NSFC Programme of China (41761011), and Biodiversity Conservation Programme of the Ministry of Ecology and Environment, China (China-BON Butterflies) (SDZXWJZ01013).

\section{Author contributions}

S.J.H. and J.M.H. conceived the present research, D.H.X. and Z.X.G. collected, analysed the data and prepared all map figures, S.J.H. wrote the main manuscript and prepared statistical figures.

\section{Competing interests}

The authors declare no competing interests.

\section{Additional information}

Supplementary information is available for this paper at https://doi.org/10.1038/s41598-019-51972-6.

Correspondence and requests for materials should be addressed to J.M.H.

Reprints and permissions information is available at www.nature.com/reprints. 
Publisher's note Springer Nature remains neutral with regard to jurisdictional claims in published maps and institutional affiliations.

(c) (i) Open Access This article is licensed under a Creative Commons Attribution 4.0 International License, which permits use, sharing, adaptation, distribution and reproduction in any medium or format, as long as you give appropriate credit to the original author(s) and the source, provide a link to the Creative Commons license, and indicate if changes were made. The images or other third party material in this article are included in the article's Creative Commons license, unless indicated otherwise in a credit line to the material. If material is not included in the article's Creative Commons license and your intended use is not permitted by statutory regulation or exceeds the permitted use, you will need to obtain permission directly from the copyright holder. To view a copy of this license, visit http://creativecommons.org/licenses/by/4.0/.

(c) The Author(s) 2019 